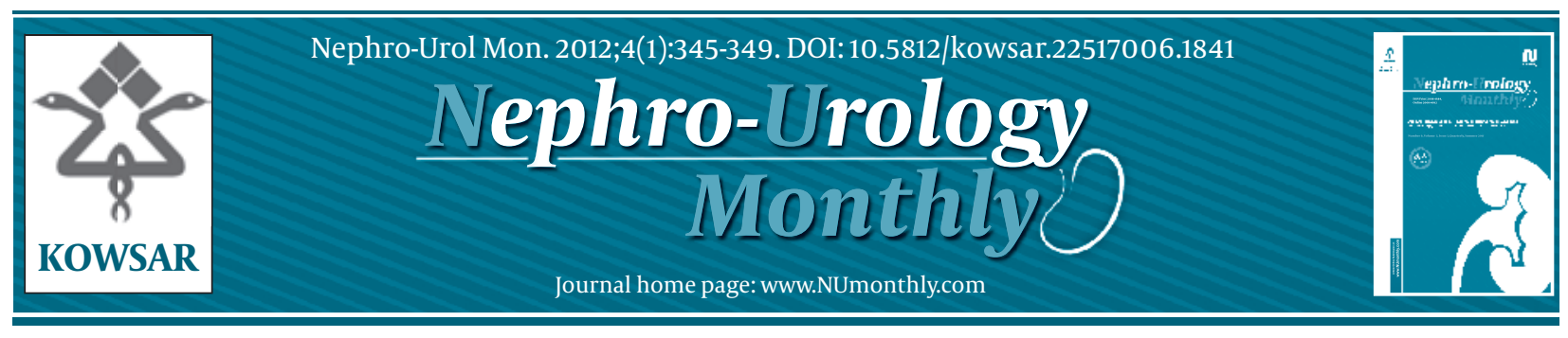

\title{
Currently Available Urine-Based Tumour Markers in the Detection of New and Recurrent Urothelial Bladder Cancer
}

\author{
Marcus Horstmann ${ }^{1 *}$ \\ ${ }^{1}$ Department of Urology, Kantonsspital Winterthur, Winterthur, Switzerland
}

\begin{tabular}{|c|c|}
\hline A R T I C L E I N F O & A B S T R A C T \\
\hline $\begin{array}{l}\text { Article type: } \\
\text { Review Article }\end{array}$ & \multirow{10}{*}{$\begin{array}{l}\text { Bladder cancer represents a major health care burden in many societies. Currently, } \\
\text { cystoscopy and urinary cytology are the gold standard in bladder cancer detection. To } \\
\text { further improve detection and/or to reduce expensive and invasive cystoscopies, highly } \\
\text { sensitive and specific urine-based tumour markers are requested. Until now, several } \\
\text { urine-based tumour markers for the detection and surveillance of bladder cancer have } \\
\text { been developed and are commercially available. Others are under research. This paper } \\
\text { gives an overview of the currently commercially available urine-based tumour makers } \\
\text { for bladder cancer. Information is based on a non-systematic PubMed literature search. } \\
\text { All markers were at least in some studies superior to urinary cytology; however, none of } \\
\text { them can be considered sensitive and specific enough alone to substantially reduce the } \\
\text { necessity of cystoscopies. The recommended use of urine-based tumour markers there- } \\
\text { fore remains in adjunction to cystoscopy and for some of them in individual screening } \\
\text { situations of patients at high risk. }\end{array}$} \\
\hline Article history: & \\
\hline Received: 06 Jul 2011 & \\
\hline Revised: 17 Jul 2011 & \\
\hline Accepted: 30 Jul 2011 & \\
\hline Keywords: & \\
\hline Urinary Bladder Neoplasms & \\
\hline Epidemiology & \\
\hline Tumor Markers, Biological & \\
\hline & \\
\hline
\end{tabular}

Copyright $\odot 2012$, Kowsar M.P.Co. All rights reserved.

Implication for health policy/practice/research/medical education:

Urine-based tumour markers might become a helpful tool in early detection of bladder cancer. This review is adressed to health professionals dealing with bladder cancer patients and patients at risk.

- Please cite this paper as:

Horstmann M. Currently Available Urine-Based Tumour Markers in the Detection of New and Recurrent Urothelial Bladder Cancer. Nephro-Urol Mon.2012;4(1):345-9. DOI: 10.5812/kowsar.22517006.1841

\section{Introduction}

Urothelial bladder cancer (BC) is the second most common urologic cancer in western societies. Approximately 380000 cases of bladder cancer are diagnosed around the world each year (1). In men it is the fourth most common and in female the seventh most common malignancy. Currently, most bladder cancers are found due to symptoms such as macrohematuria or dysuria. Following a symptom-based diagnostic, in about $75 \%$ of the patients none muscle invasive bladder cancer (NMIBC, pTa-pT1 or Cis) is found at first diagnosis (2). In this state of the disease it can most often be managed by transurethral bladder resection alone or in combination with lo-

\footnotetext{
* Corresponding author: Marcus Horstmann, Kantonsspital Winterthur Department of Urology, Brauerstr 15, 8401 Winterthur, Switzerland. Tel: +52-2664171, Fax: +52-26645003, E-mail : marcushorstmann@gmx.ch

DOI:10.5812/kowsar.22517006.1841

Copyright $\odot 2012$, Kowsar M.P.Co. All rights reserved.
}

cal chemotherapy or BCG instillations. Because of a high recurrence rate of approximately $50 \%$ and a high progression rate of about $10-15 \%$ over a period a 5 years, NMIBC needs life long surveillance consisting of cytology and cystoscopies (2). Because cystoscopies are invasive, cause discomfort and pain for the patient (3), BC surveillance is often perceived by the patients as a major burden with a high impact on quality of life (4).

In this situation highly sensitive and specific urine based tumour markers are considered a possible solution and additionally might reduce health care costs depending on their prices and the prices for cystoscopies in different health care systems (5). In case of muscle invasive disease (T2 or higher) which accounts for about $25 \%$ of newly detected bladder cancer, metastasis become more probable and the disease often requires according to the individual patient situation radical cystectomy (6). To reduce this relatively high number of advanced BCs at first diagnosis, detection at earlier stages should 
be the aim. In this situation an ideal urine-based tumour marker would be of high value because it might offer a non-invasive diagnostic tool that could be used to examine large cohorts of patients. Until now due to the lack of such powerful screening tools, bladder cancer screening is not recommended by medical societies in a general population (7-9). However there is some evidence that early detection of BC might reduce stage at first diagnosis and improve outcome of the patients (10). That is why, if not in a general population, several authors propose screening in high-risk populations in which a higher prevalence of the disease might allow an efficient screening $(11,12)$. For BC such high-risk populations can be easily defined due to known risk factors, such as smoking, chemical exposure (mostly work related), age and male gender (6). However further studies - preferably randomized studies - are needed to prove its efficiency which mainly seems to depend on the performance of the screening tool. Currently no such randomized studies for bladder cancer screening are available.

Reliable urine-based tumour markers are strongly needed, because of the disadvantages of the current standard urine based diagnostic tool: urinary cytology. Especially in low grade cancer it has a weak sensitivity and remains an investigator dependent examination (13). Currently several urine-based tumour markers are commercially available and approved by the U.S. Food and Drug Administration (FDA) among them: NMP22, NMP22BladderChek, BTA TRAK, BTA stat, ImmunoCyt/ uCyt + and UroVysion (14-17). This review tries to give an overview of the currently available urine-based tumour markers with regard to their performance and indication in bladder cancer detection. Information is based on a non-systematic PubMed literature search between 2000-2011.

\section{Currently Available Urine-Based Tumour Markers for Bladder Cancer(FDAApproved)}

\subsection{NMP22}

Nuclear Matrix Protein 22 (NMP22) is a nuclear mitotic apparatus protein involved in the distribution of the chromatin to offspring cells, and it is located in the nuclear matrix of all cell types. NMP22 is released from the nuclei of the tumour cells during apoptosis (18). Patients with bladder cancer have 25 times more NMP22 in their urine than normal individuals (18). Currently two tests for measuring NMP22 in voided urine are available: the original laboratory-based, quantitative enzyme immunoassay NMP22 bladder cancer test kit (Matritech Inc, Newton, MA, US) and the qualitative point-of-care test NMP22 BladderChek (Matritech, US). Both tests are FDA approved, the original immunoassay since 1996 for diagnosis of recurrence and since 2000 for diagnosis of suspected BC; NMP22 BladderChek is FDA approved for both diagnosis (2002) and screening (2003) (14). The reported sensitivity of the original tests ranges from $47-100 \%$, specificity from $60-90 \%$ depending on cut-off values and the selected pa- tients groups (19-23). Several benign conditions, such as urinary infection, urolithiasis, bowel interposition, foreign bodies (catheter) and recent urological instrumentation were identified as exclusion criteria as they significantly reduced specificity of the test and were responsible for false positive values (24). In comparison to the immunoassay, slightly reduced sensitivity and specificity values were published for NMP22 BladderChek with however the advantage of it being an easy, rapid and investigator independent point-of-care test. In a recent multi-centre study by Grossmann et al it was shown that NMP22 could improve the detection of bladder cancer in adjunction to cystoscopy (25). In this study NMP22 revealed a better sensitivity than cytology, which was only $16 \%$.

\subsection{ImmunoCyt/uCyt ${ }^{+}$}

The ImmunoCyt test (DiagnoCure Inc, Quebec, Canada) is an immunocytochemical test performed on exfoliated urothelial cells of voided urine to better visualize in combination with urinary cytology malignant urothelial cells. Therefore fluorescent monoclonal antibodies against carcinoembryonic antigen and two bladder cancer associated mucins which are mostly absent in normal urothelium are used (26). ImmunoCyt requires a relatively large number of cells and a fully equipped laboratory with trained personnel. Reported sensitivities range from approximately 55-72\% in detecting low-grade tumours and $76 \%$ in high grade disease (14). Specificity is reported between $69 \%$ and $79 \%$ (27-29). ImmunoCyt was superior to cytology in sensitivity but revealed a worse specificity in most studies. ImmunoCyt is FDA approved for the diagnosis of bladder cancer, but recommended only in adjunction to cystoscopy in bladder cancer surveillance (15).

\subsection{UroVysion}

UroVysion (Vysis Chicago, IL, US) is a multi-probe fluorescence in situ hybridization (FISH) test to detect the aneuploidy of the chromosomes 3,7, and 17 and the loss (deletion) of the 9p21 gene in exfoliated bladder tumour cells via fluorescence in situ hybridization. For evaluation a minimum of 25 abnormal urothelial cells are investigated. If $\geq 4$ cells show polysomy of the above mentioned chromosomes or identify loss of 9p21, the test is considered positive. Until now several studies and reviews revealed a higher sensitivity of FISH when compared to cytology. In a metaanalysis Hajdinjak et al. described a significant better overall performance of FISH than of cytology (area under the curve $0.87 \mathrm{vs.} 0.63$ ) (30). For low grade tumours sensitivity ranged from 36-57\% and for high grade tumours from 83-97\% (31, 32). In direct comparisons to BTA stat and NMP22 UroVysion revealed a better sensitivity than the other tests $(33,34)$. With regard to specificity, however, some studies showed a slightly reduced specificity in comparison to cytology (35).

Regarding apparently false positive values some authors hypothesized, that a positive FISH test would pre- 


\begin{tabular}{lll}
\hline \multicolumn{2}{l}{ Table. Currently Reported Sensitivity and Specificity of the Available Urine-Based Tumour Markers in Bladder Cancer $(14-16,45)$} \\
\hline & Sensitivity, range, $\%$ & Specificity, range, \% \\
\hline Cytology & $13-75$ & $81-100$ \\
NMP22 Elisa & $47-100$ & $60-90$ \\
NMP22 BladderChek & $50-86$ & 85 \\
lmmunoCyt/Cyt ${ }^{+}$ & $55-76$ & $69-79$ \\
UroVysion & $36-97$ & $63-95$ \\
BTA stat & $36-78$ & $50-90$ \\
BTA TRAK & $51-100$ & $50-90$ \\
\hline
\end{tabular}

cede endoscopic tumour recurrence on a molecular level and consequently found tumour recurrence in $85-89 \%$ of the patients with "false positive" tests $(36,37)$. Others, however, found contradicting results (34).

UroVysion is FDA approved since 2002 for diagnosis and since 2005 for bladder cancer screening (14). High costs, the need for fully equipped laboratory and the relatively time consuming procedure have until now limited the widespread use of this test.

\subsection{Bladder Tumour Antigen Test (BTA stat/BTA TRAK)}

Both, BTA stat and BTA TRAK (Polymedco, Courtlandt Manor, NY, US) detect human complement factor $\mathrm{H}$ in voided urine by two monoclonal antibodies X13.2. and $\mathrm{X} 52.1$. Factor $\mathrm{H}$ protein is a $155-\mathrm{kDa}$ protein that is shed into urine by tumour cells to presumably prevent complement-mediated cell death. The BTA stat is a qualitative, point of care test with immediate results whereas BTA TRAK is a quantitative immunoassay that requires trained personnel and a reference laboratory (38). Both tests are approved for diagnosis in bladder cancer since 1997 and 1998, respectively (14). For BTA stat a sensitivity of $36-78 \%$ is reported and for BTA TRAK of $51-100 \%$. Specificity for both tests ranges between $50-90 \%(39,40)$. However, specificity was found to be significantly lower in other urological disease and conditions such as haematuria, urinary tract infection, previous BCG treatment and urolithiasis $(17,41)$. BTA stat proved to be more sensitive in low grade cancer than cytology (42). Especially in combination with cytology an improved sensitivity was observed. However, due to the low specificity because of numerous confounding factors both tests are not recommended without cystoscopy (Table).

\section{Conclusions}

The low sensitivity of urinary cytology at least in low grade tumours and its investigator dependence have prompted the development of numerous urine-based tumour markers for bladder cancer. In the present review currently commercially available and approved markers were summarized. Even though all makers were shown to be more sensitive than cytology, none of them can be considered powerful enough to replace cystoscopy. Their current role remains in adjunction to cystoscopy. In this situation some markers like for example NMP22 have proven their benefit as shown by Grossman et al. (25). In their study, the additional use of NMP22 in combination with cystoscopy detected more tumours than cystoscopy alone. This takes into account that even cystoscopy as the current gold standard does not result in a sensitivity of $100 \%$ and misses some bladder cancers. However, if markers are used only in adjunction to cystoscopy, the question arises if the achieved benefit justifies the additional costs. This is especially true for expensive and laboratory dependent markers such as ImmunCyt and UroVysion (43).

Generally in the evaluation of urine based tumour markers, detection of new bladder cancers should be differentiated from bladder cancer surveillance (16). Whereas in both situations overall sensitivity is of high importance in order not to miss a tumour, sensitivity in low grade cancer and specificity seems to be less important in BC surveillance. In the detection of new bladder cancers, a high number of "false positive" test would prompt numerous unnecessary additional investigations such as repeated cystoscopies, CT-scans etc., which would create harm for the patient and costs. In contrast to that in BC surveillance this would be less important as in any way patients would undergo repeated cystoscopies. Whereas, in surveillance the main focus should be put on the early detection of high grade cancers and a reduced sensitivity in low grade cancers might be acceptable, this is less true for the detection of new bladder cancers. In these cases, any cancer should be detected because most patients will not undergo further urological follow-up once a cancer is ruled out.

Currently the surveillance generally - regardless of tumour stage or grade - includes repeated cystoscopies every 3-4 month during the first 2 years, then every 6 month for 5 years and yearly afterwards (16). Especially, in low risk tumours urine based tumour markers might be more useful than cytology to extend the intervals between cystoscopies as they offer a higher sensitivity and better negative predictive value. Lodde et al. safely reduced cystoscopies in their surveillance protocol to yearly cystoscopies after an initial cystoscopy at 3 months using additionally every 6 months an ImmunoCyt test (44). Even though 30 out of 84 patients developed tumour recurrence, no tumour progression was observed and all recurrent lesions found were again staged pTaG1. This way the costs were reduced and at the same time patients were not put at risk for disease progression. In such stud- 
ies, it remains however questionable what would have happened if cystoscopies were reduced without the use of an additional marker. Such a control arm was unfortunately not included in the presented study.

As both the detection and surveillance sensitivity of the described markers are far from $100 \%$, another way to improve sensitivity might be the combination of tumour markers. As shown in a recent study by us the combination of NMP22, UroVysion, ImmunoCyt and Cytology increased in various marker panels of 2-4 markers the sensitivity in BC surveillance up to $98 \%$, however, at the expense of a decreased specificity and increased costs (45). This approach seems to be mainly useful in a surveillance situation in which a reduced specificity might be judged acceptable as mentioned above.

Because initially urine based markers were intended to replace or at least significantly reduce cystoscopies, special attention has to be given to specificity and the rate of "false positive tests" as this might trigger at least in screening populations even more cystoscopies (15). This problem is especially true for protein based tests as BTAstat and NMP22 which are known for their lower specificity. In them several benign conditions (urolithiasis, infection, urological instrumentation, catheters etc.) were shown to result in positive tests with a high risk of "false positive" tests. As a consequence they should be carefully used only after exclusion of these conditions to avoid unnecessary false positive tests. However, these exclusion criteria make their widespread use especially in screening populations difficult as in general, little is known about concomitant clinical conditions in these groups of patients.

Regarding the UroVysion test several investigators had a closer look at patients with a "false positive" test and found that later on patients with a false positive test would result in tumour recurrence. Therefore, these positive tests were interpreted by some authors as "anticipatory positive" test reflecting the already altered urothelium due to the disease (46). However, it has to be critically remarked that these "positive test" also have to be judged in the perspective that because of the limited sensitivity of cystoscopy also some tumours might have been missed at the initial evaluation.

All in all, even though there is currently no clear recommendation for the use of urine-based tumour markers by urological societies $(2,9)$, they remain an important topic in urology. As discussed above, none of the markers has revolutionized urology by replacing cystoscopy; therefore cystoscopy in combination with cytology still remains the gold standard for the detection of BC. However, as several interesting investigational markers are under clinical research $(14,47)$ it remains to be seen if more sensitive and specific markers will emerge and their widespread use will be justified.

\section{Acknowledgments}

None declared.

\section{Financial Disclosure}

None declared.

\section{Funding/Support}

None declared.

\section{References}

1. Parkin DM, Bray F, Ferlay J, Pisani P. Global cancer statistics, 2002. CA Cancer J Clin. 2005;55(2):74-108.

2. Babjuk M, Oosterlinck W, Sylvester R, Kaasinen E, Bohle A, Palou-Redorta J, et al. EAU guidelines on non-muscle-invasive urothelial carcinoma of the bladder, the 2011 update. Eur Urol. 2011;59(6):997-1008.

3. Almallah YZ, Rennie CD, Stone J, Lancashire MJ. Urinary tract infection and patient satisfaction after flexible cystoscopy and urodynamic evaluation. Urology. [Research Support, Non-U.S. Gov't]. 2000;56(1):37-9.

4. van der Aa MN, Steyerberg EW, Sen EF, Zwarthoff EC, Kirkels WJ, van der Kwast TH, et al. Patients' perceived burden of cystoscopic and urinary surveillance of bladder cancer: a randomized comparison. BJU Int. [Comparative Study Randomized Controlled Trial Research Support, Non-U.S. Gov't]. 2008;101(9):1106-10.

5. Sievert KD, Amend B, Nagele U, Schilling D, Bedke J, Horstmann $\mathrm{M}$, et al. Economic aspects of bladder cancer: what are the benefits and costs? World J Urol. [Review]. 2009;27(3):295-300.

6. Horstmann M, Witthuhn R, Falk M, Stenzl A. Gender-specific differences in bladder cancer: a retrospective analysis. Gend Med. [Comparative Study]. 2008;5(4):385-94.

7. Screening for Bladder Cancer [database on the Internet]. [cited 2009]. Available from: www.ctfphc.org.

8. NCCN Clinical Practice Guidelines in Oncology. Bladder Cancer including Upper Tract Tumors an Urothelial Carcinoma of the Prostate [database on the Internet]. [cited 2009]. Available from: www.nccn.org.

9. Bladder Cancer Clinical Guideline. Chapter 1: The Managment of Bladder Cancer: Diagnosis and Treatment Recommendations [database on the Internet]. [cited 2009]. Available from: www. auanet.org.

10. Messing EM, Teot L, Korman H, Underhill E, Barker E, Stork B, et al. Performance of urine test in patients monitored for recurrence of bladder cancer: a multicenter study in the United States. J Urol. [Multicenter Study Research Support, Non-U.S. Gov't]. 2005;174(4 Pt1):1238-41.

11. Zlotta AR, Roumeguere T, Kuk C, Alkhateeb S, Rorive S, Lemy A, et al. Select screening in a specific high-risk population of patients suggests a stage migration toward detection of non-muscleinvasive bladder cancer. Eur Urol. 2011;59(6):1026-31.

12. Lotan Y, Svatek RS, Sagalowsky AI. Should we screen for bladder cancer in a high-risk population?: A cost per life-year saved analysis. Cancer. [Evaluation Studies]. 2006;107(5):982-90.

13. Lotan Y, Roehrborn CG. Sensitivity and specificity of commonly available bladder tumor markers versus cytology: results of a comprehensive literature review and meta-analyses. Urology. [Review]. 2003;61(1):109-18; discussion 18.

14. Lintula S, Hotakainen K. Developing biomarkers for improved diagnosis and treatment outcome monitoring of bladder cancer. Expert Opin Biol Ther. [Review]. 2010;10(8):1169-80.

15. Tilki D, Burger M, Dalbagni G, Grossman HB, Hakenberg OW, Palou J, et al. Urine Markers for Detection and Surveillance of NonMuscle-Invasive Bladder Cancer. Eur Urol. 2011; 60(3): 484-92.

16. Budman LI, Kassouf W, Steinberg JR. Biomarkers for detection and surveillance of bladder cancer. Can Urol Assoc J. 2008;2(3):212-21.

17. Feil G, Stenzl A. [Tumor marker tests in bladder cancer]. Actas Urol Esp. [Review]. 2006;30(1):38-45.

18. Palous J. PM, Consentino M., Caicedo J.I., Rodriguez O, Vallavicencio $\mathrm{H}$. Effect of retention time on NMP22 bladde chek assay results in voided urine. Nephro-Urol Mon. 2011;3(3):3.

19. Hughes JH, Katz RL, Rodriguez-Villanueva J, Kidd L, Dinney C, Grossman HB, et al. Urinary nuclear matrix protein 22 (NMP22): 
a diagnostic adjunct to urine cytologic examination for the detection of recurrent transitional-cell carcinoma of the bladder. Diagn Cytopathol.1999;20(5):285-90.

20. Miyanaga N, Akaza H, Tsukamoto T, Ishikawa S, Noguchi R, Ohtani $\mathrm{M}$, et al. Urinary nuclear matrix protein 22 as a new marker for the screening of urothelial cancer in patients with microscopic hematuria. Int J Urol.1999;6(4):173-7.

21. Ramakumar S, Bhuiyan J, Besse JA, Roberts SG, Wollan PC, Blute ML, et al. Comparison of screening methods in the detection of bladder cancer. J Urol. [Clinical Trial Comparative Study]. 1999;161(2):388-94.

22. Stampfer DS, Carpinito GA, Rodriguez-Villanueva J, Willsey LW, Dinney CP, Grossman HB, et al. Evaluation of NMP22 in the detection of transitional cell carcinoma of the bladder. $J$ Urol. 1998;159(2):394-8.

23. Soloway MS, Briggman V, Carpinito GA, Chodak GW, Church PA, Lamm DL, et al. Use of a new tumor marker, urinary NMP22, in the detection of occult or rapidly recurring transitional cell carcinoma of the urinary tract following surgical treatment.J Urol. [Clinical Trial]. 1996;156(2 Pt 1):363-7.

24. Sharma S, Zippe CD, Pandrangi L, Nelson D, Agarwal A. Exclusion criteria enhance the specificity and positive predictive value of NMP22 and BTA stat. JUrol. 1999;162(1):53-7.

25. Grossman HB, Messing E, Soloway M, Tomera K, Katz G, Berger $\mathrm{Y}$, et al. Detection of bladder cancer using a point-of-care proteomic assay. Jama. [Comparative Study Multicenter Study Research Support, Non-U.S. Gov't]. 2005;293(7):810-6.

26. Feil G, Zumbragel A, Paulgen-Nelde HJ, Hennenlotter J, Maurer S, Krause S, et al. Accuracy of the ImmunoCyt assay in the diagnosis of transitional cell carcinoma of the urinary bladder. Anticancer Res. 2003;23(2A):963-7.

27. Olsson $\mathrm{H}$, Zackrisson B. ImmunoCyt a useful method in the follow-up protocol for patients with urinary bladder carcinoma. Scand J Urol Nephrol. [Research Support, Non-U.S. Gov't]. 2001;35(4):280-2.

28. Vriesema JL, Atsma F, Kiemeney LA, Peelen WP, Witjes JA, Schalken JA. Diagnostic efficacy of the ImmunoCyt test to detect superficial bladder cancer recurrence. Urology. [Clinical Trial]. 2001;58(3):367-71.

29. Mian C, Pycha A, Wiener H, Haitel A, Lodde M, Marberger M. Immunocyt: a new tool for detecting transitional cell cancer of the urinary tract. J Urol. [Clinical Trial Research Support, Non-U.S. Gov't]. 1999;161(5):1486-9.

30. Hajdinjak T. UroVysion FISH test for detecting urothelial cancers: meta-analysis of diagnostic accuracy and comparison with urinary cytology testing. Urol Oncol. [Comparative Study MetaAnalysis]. 2008;26(6):646-51.

31. Lokeshwar VB, Habuchi T, Grossman HB, Murphy WM, Hautmann SH, Hemstreet GP, 3rd, et al. Bladder tumor markers beyond cytology: International Consensus Panel on bladder tumor markers. Urology. [Consensus Development Conference Research Support, N.I.H., Extramural]. 2005;66(6 Suppl 1):35-63.

32. Habuchi T, Marberger M, Droller MJ, Hemstreet GP, 3rd, Grossman HB, Schalken JA, et al. Prognostic markers for bladder cancer: International Consensus Panel on bladder tumor markers. Urology. [Consensus Development Conference Research Support, N.I.H., Extramural]. 2005;66(6 Suppl 1):64-74.

33. Friedrich MG, Toma MI, Hellstern A, Pantel K, Weisenberger DJ, Noldus J, et al. Comparison of multitarget fluorescence in situ hybridization in urine with other noninvasive tests for detecting bladder cancer. BJU Int. [Comparative Study Evaluation Stud- ies]. 2003;92(9):911-4.

34. Sarosdy MF, Schellhammer P, Bokinsky G, Kahn P, Chao R, Yore $\mathrm{L}$, et al. Clinical evaluation of a multi-target fluorescent in situ hybridization assay for detection of bladder cancer. J Urol. [Clinical Trial Evaluation Studies Multicenter Study Research Support, Non-U.S. Gov't]. 2002;168(5):1950-4.

35. Laudadio J, Keane TE, Reeves HM, Savage SJ, Hoda RS, Lage JM, et al. Fluorescence in situ hybridization for detecting transitional cell carcinoma: implications for clinical practice. BJU Int. [Evaluation Studies]. 2005;96(9):1280-5.

36. Gofrit ON, Zorn KC, Silvestre J, Shalhav AL, Zagaja GP, Msezane LP, et al. The predictive value of multi-targeted fluorescent in-situ hybridization in patients with history of bladder cancer. Urol Oncol. 2008;26(3):246-9.

37. Skacel M, Fahmy M, Brainard JA, Pettay JD, Biscotti CV, Liou LS, et al. Multitarget fluorescence in situ hybridization assay detects transitional cell carcinoma in the majority of patients with bladder cancer and atypical or negative urine cytology. I Urol. [Evaluation Studies Research Support, Non-U.S. Gov't]. 2003;169(6):2101-5.

38. Heicappell R, Wettig IC, Schostak M, Muller M, Steiner U, Sauter $\mathrm{T}$, et al. Quantitative detection of human complement factor H-related protein in transitional cell carcinoma of the urinary bladder. Eur Urol. [Comparative Study]. 1999;35(1):81-7.

39. Schroeder GL, Lorenzo-Gomez MF, Hautmann SH, Friedrich MG, Ekici S, Huland $\mathrm{H}$, et al. A side by side comparison of cytology and biomarkers for bladder cancer detection. J Urol. [Comparative Study Research Support, Non-U.S. Gov't Research Support, U.S. Gov't, P.H.S.]. 2004;172(3):1123-6.

40. Babjuk M, Kostirova M, Mudra K, Pecher S, Smolova H, Pecen L, et al. Qualitative and quantitative detection of urinary human complement factor $\mathrm{H}$-related protein (BTA stat and BTA TRAK) and fragments of cytokeratins 8, 18 (UBC rapid and UBC IRMA) as markers for transitional cell carcinoma of the bladder. Eur Urol. [Comparative Study Research Support, Non-U.S. Gov't]. 2002;41(1):34-9.

41. Mahnert B, Tauber S, Kriegmair M, Schmitt UM, Hasholzner U, Reiter W, et al. BTA-TRAK-a useful diagnostic tool in urinary bladder cancer? Anticancer Res. [Comparative Study]. 1999;19(4A):2615-9.

42. Raitanen MP. The role of BTA stat Test in follow-up of patients with bladder cancer: results from FinnBladder studies. World J Urol. [Comparative Study Multicenter Study Research Support, Non-U.S. Gov't]. 2008;26(1):45-50.

43. Svatek RS, Sagalowsky AI, Lotan Y. Economic impact of screening for bladder cancer using bladder tumor markers: a decision analysis. Urol Oncol. 2006;24(4):338-43.

44. Lodde M, Mian C, Comploj E, Palermo S, Longhi E, Marberger $\mathrm{M}$, et al. uCyt+ test: alternative to cystoscopy for less-invasive follow-up of patients with low risk of urothelial carcinoma. Urology. [Comparative Study]. 2006;67(5):950-4.

45. Horstmann M, Patschan O, Hennenlotter J, Senger E, Feil G, Sten$\mathrm{zl} \mathrm{A}$. Combinations of urine-based tumour markers in bladder cancer surveillance. Scand J Urol Nephrol. 2009;43(6):461-6.

46. Friedrich MG, Hellstern A, Toma MI, Hammerer P, Huland H. Are false-positive urine markers for the detection of bladder carcinoma really wrong or do they predict tumor recurrence? Eur Urol. [Comparative Study]. 2003;43(2):146-50; discussion 50-1.

47. Horstmann M, Bontrup H, Hennenlotter J, Taeger D, Weber A, Pesch B, et al. Clinical experience with survivin as a biomarker for urothelial bladder cancer. World J Urol. 2010;28(3):399-404. 